\title{
ADSORÇÃO DE IgG HUMANA EM QUITOSANA/ALGINATO EPOXIDADO COM CORANTES REATIVO AZUL 4 E REATIVO VERDE 5 IMOBILIZADOS
}

\author{
N. A. Dias ${ }^{1}$; D. R. Gondim ${ }^{1}$; B. T. C. Bezerra ${ }^{1}$; I. T. L. Bresolin ${ }^{2}$; D. C. S. Azevedo ${ }^{1}$; I. J. Silva \\ $\mathrm{Jr}^{1}$. \\ ${ }^{1}$ Universidade Federal do Ceará, Departamento de Engenharia Química \\ E-mail para contato: ivanildo@gpsa.ufc.br \\ ${ }^{2}$ Universidade Federal de São Paulo, Departamento de Ciências Exatas e da Terra
}

\begin{abstract}
RESUMO - O objetivo deste trabalho foi comparar a capacidade de adsorção das imunoglobulinas do isotipo $\mathrm{G}$ (IgGs) em quitosana/alginato epoxidado com os corantes reativo azul $4\left(\mathrm{QAE}_{\mathrm{a}}\right)$ e reativo verde $5\left(\mathrm{QAE}_{\mathrm{v}}\right)$ imobilizados. Inicialmente foram realizados estudos em batelada para investigar a influência da variação do $\mathrm{pH}$ na adsorção de IgG em diferentes tampões (MES, MOPS, HEPES, TRIS/HCl) com força iônica de $25 \mathrm{mM}$. Os perfis de isoterma de adsorção de IgG foram similares com destaque ao perfil com o tampão TRIS/HCl ( $\mathrm{pH} 7,2$ ), onde as quantidades de IgG adsorvidas nos adsorventes QAEa e QAEv foram acima de $250 \mathrm{mg} / \mathrm{g}$, valor bem superior dos demais tampões estudados. Os modelos de Langmuir e Langmuir-Freundlich se ajustaram aos dados experimentais e foram importantes para obtenção dos parâmetros de equilíbrio. As constantes de dissociação $\left(K_{D}\right.$ e $\left.K_{D L F}\right)$ para ambos adsorventes tiveram valores na ordem de $10^{-6} \mathrm{M}$ indicando que os corantes atuam como ligantes de afinidade. Os resultados para o leito fixo foram muito promissores, pois foi verificado um elevado percentual de IgG retida nos dois adsorventes, acima de $85 \%$ da massa injetada diluída nos tampões MOPS (pH 6,5) e HEPES (pH 6,8).
\end{abstract}

\section{INTRODUÇÃO}

Anticorpos pertencem a uma classe de moléculas que formam aproximadamente $20 \%$ do plasma do plasma das proteínas do corpo humano, a classe das Imunoglobulinas. Todas elas possuem uma estrutura em comum, que consiste em quatro cadeias polipeptídicas: duas cadeias pesadas e idênticas (H) e outras duas leves e idênticas (L) (Amersham Biosciences, 2002).

As imunoglobulinas são separadas em cinco classes de acordo com os componentes das suas cadeias pesadas: IgG, IgA, IgM, IgD e IgE. A IgG é dividida em quatro subclasses IgG1, IgG2, IgG3 e IgG4. A diferença entre esses tipos está na sequência dos aminoácidos contidos em cada classe (Amersham Biosciences, 2002). Essas proteínas são indicadas para o tratamento de câncer, doenças infecciosas, deficiência seletiva de anticorpos, entre outros, mas isso requer uma quantidade grande e significativa de proteína de alta pureza (Burnouf and Radosevich 2001). A 


\section{9 a 22 de outubro de 2014 \\ Florianópolis/SC}

cromatografia de afinidade é uma técnica de adsorção que explora a relação entre um ligante imobilizado e a molécula que será separada (Vijayalakshmi, 1989). Esse procedimento é considerado o método mais eficiente de purificação de proteínas.

Corantes imobilizados em diferentes matrizes cromatográficas têm sido utilizados como ligantes de afinidade para adsorção de proteína (Yavuz et al., 2006, Bayramoglu et al., 2007, Wongchuplan et al., 2009., Gondim et al., 2012) devido a elevada especificidade desses por domínios específicos das proteínas. Desta forma, o objetivo deste trabalho foi investigar e comparar a capacidade de adsorção de Imunoglobulina Humana do isotipo $\mathrm{G}$ em Reativo Verde 5 e Reativo Azul 4 imobilizados em quitosana/alginato epoxidado em diferentes sistemas tamponantes. $\mathrm{O}$ efeito do $\mathrm{pH}$ e isotermas de adsorção foram avaliados em tanques agitados. $\mathrm{O}$ desempenho em leito fixo foi estudado com a finalidade de averiguar o potencial dessas fases estacionárias em reter IgG.

\section{MATERIAIS E MÉTODOS}

\subsection{Materiais}

2.1.1 Reagentes: Os corantes Reativo Azul 4 e Reativo Verde 5, Epicloridrina (99\%), MOPS (ácido morfolinopropanosulfônico), HEPES (ácido N-2-hidroxietilpiperazino-N'-2etanosulfônico), MES (ácido morfolinoetanosulfônico), Trizma/HCl (TRIS/HCl) e IgG humana foram obtidos da Sigma-Aldrich (EUA). A quitosana em pó utilizada foi da Polymar (BRASIL). Os outros reagentes utilizados foram todos de grau analítico e para a preparação de todas as soluções utilizou-se a água ultrapura MiliQ (Milipore, EUA). O termo QAE refere-se ao compósito de quitosana-alginato epoxidado, e o $\mathrm{QAE}_{\mathrm{a}}$ ou $\mathrm{QAE}_{\mathrm{v}}$ refere-se aos corantes reativos (verde/azul) imobilizados nesse compósito.

\subsection{Métodos}

2.2.1 Ensaios em batelada: Os ensaios de adsorção foram realizados em duplicata, em um sistema de agitação rotatório (TECNAL, modelo TE-165), a temperatura de $22{ }^{\circ} \mathrm{C}\left( \pm 2^{\circ} \mathrm{C}\right)$. Foram adicionados $15 \mathrm{mg}$ do adsorvente em tubos de acrílico juntamente com $3 \mathrm{~mL}$ da solução da proteína estudada em tampão. Utilizaram-se os tampões MES, MOPS, HEPES e TRIS/HCl com força iônica de $25 \mathrm{mM}$ para encontrar o $\mathrm{pH}$ que ocorre as maiores quantidades adsorvidas, sempre respeitando a faixa de $\mathrm{pH}$, indicada pelo fabricante, de cada tampões utilizado.

2.2.2 Efeito do $\mathrm{pH}$ na adsorção de proteínas: O sistema permaneceu sob agitação constante durante o período de duas horas. Ao final do tempo, as amostras foram coletadas e centrifugadas em microcentrífuga (CT-15000R CIENTEC) por 10 min com rotação igual a $10000 \mathrm{rpm}$ e a absorbância foi lida para cada amostra. Os valores foram convertidos para concentração a partir de uma curva de calibração previamente obtida para cada um dos tampões. A quantidade de proteína de alta pureza adsorvida foi calculada por meio de um balanço de massa, sendo a equação 1 descrita a seguir: 


$$
q^{*}=\frac{\mathrm{V}_{\mathrm{SOL}}\left(\mathrm{C}_{0}-\mathrm{C}_{\mathrm{EQ}}\right)}{\mathrm{m}_{\mathrm{ads}}}
$$

em que $q^{*}$ é a quantidade de proteína adsorvida por grama de adsorvente $(\mathrm{mg} / \mathrm{g}), \mathrm{C}_{\mathrm{EQ}}$ é a concentração de proteína na fase líquida $(\mathrm{mg} / \mathrm{mL})$ em equilíbrio $\operatorname{com} q^{*}, \mathrm{C}_{\mathrm{O}}$ é a concentração inicial de proteína na fase líquida $(\mathrm{mg} / \mathrm{mL}), \mathrm{m}_{\mathrm{ads}}$ é a massa de adsorvente $(\mathrm{g})$ e $\mathrm{V}_{\mathrm{SOL}}$ é o volume da solução $(\mathrm{mL})$ para o contato com o adsorvente.

2.2.3 Isotermas de adsorção: As concentrações de proteínas utilizadas nos experimentos variaram de 0,5 à $10 \mathrm{mg} / \mathrm{mL}$. As isotermas mais utilizadas atualmente para descrever o equilíbrio sólido-líquido das proteínas são as de Langmuir (Equação 2) e Langmuir-Freundlich (Equação 3). Essas isotermas têm permitido uma correta descrição dos dados experimentais de equilíbrio em vários estudos envolvendo soluções diluídas de um componente fortemente adsorvido em um adsorvente puro.

$$
\begin{aligned}
& \mathrm{q}=\frac{\mathrm{q}_{\mathrm{m}} \mathrm{C}_{\text {eq }}}{\mathrm{K}_{\mathrm{D}}+\mathrm{C}_{\text {eq }}} \\
& \mathrm{q}=\frac{\mathrm{q}_{\mathrm{m}}\left(\mathrm{C}_{\mathrm{eq}}\right)^{n}}{\mathrm{~K}_{\mathrm{DLF}}+\left(\mathrm{C}_{\text {eq }}\right)^{n}}
\end{aligned}
$$

em que $q_{m}$ é a capacidade máxima de proteínas adsorvidas, em $\mathrm{mg}^{-1} \mathrm{~g}^{-1}, K_{D}$ e $K_{D L F}$ são as constantes de dissociação, e de dissociação aparente, respectivamente, expressas em mol/L ou M, a qual indica a afinidade entre proteína e adsorvente, e $n$ é a constante de Langmuir-Freundlich, a qual indica a cooperatividade efetiva presente no sistema de adsorção.

2.2.4 Ensaios em leito fixo: Os experimentos cromatográficos com a proteína $\operatorname{IgG}$ foram realizados nas seguintes condições: volume de injeção de $10,0 \mathrm{~mL}$ e concentração $1,0 \mathrm{mg} / \mathrm{mL}$ de $\mathrm{IgG}$, vazão $0,8 \mathrm{~mL} / \mathrm{min}$ e massa de adsorvente $\left(\mathrm{QAE}_{\mathrm{a}}\right.$ ou $\left.\mathrm{QAE}_{\mathrm{v}}\right)$ de $0,5 \mathrm{~g}$. A solução de $\mathrm{IgG}$ foi preparada nos tampões MOPS, HEPES e TRIS/HCl $25 \mathrm{mM}$. A eluíção foi realizada com adição do sal $\mathrm{NaCl}$ 1,0 M ao tampão de corrida.

\section{DISCUSSÃO E RESULTADOS}

\subsection{Estudo do $\mathrm{pH}$ na adsorção de IgG em $\mathrm{QAE}_{\mathrm{a}}$ e $\mathrm{QAE}_{\mathrm{v}}$}

$\mathrm{O}$ estudo do $\mathrm{pH}$ na adsorção de biomoléculas é um resultado necessário haja vista que cada proteína possui um ponto isoelétrico (pI) próprio. $\mathrm{O} \mathrm{pI}$ da proteína é o $\mathrm{pH}$ onde há um balanceamento de cargas e normalmente a maior adsorção ocorre no pI ou em valores próximos ao pI. Observa-se nas Figuras 1 e 2 o comportamento da adsorção de IgG nos dois materiais $\left(\mathrm{QAE}_{\mathrm{a}}\right.$ e $\left.\mathrm{QAE}_{\mathrm{v}}\right)$ nos diferentes sistemas tamponantes. Observou-se que no tampão TRIS/HCl a adsorção de $\mathrm{IgG}$ foi bem superior frente aos demais e o pH de maior adsorção foi o 7,2. Para os 
outros tampões tivemos a maior adsorção nos pHs 6,7 (MES), 6,5 (MOPS) e 6,8 (HEPES). Constatou-se que o $\mathrm{pH}$ de maior adsorção de $\mathrm{IgG}$ foi próximo para todos os tampões. Uma provável explicação deve-se ao pI da IgG que não é fixo e está compreendido no intervalo de 6,3 à 9,0 (Bresolin et al., 2010). A IgG possui um pI variável devido as suas quatro subclasses que a compõe, $\operatorname{IgG}_{1}, \mathrm{IgG}_{2}, \mathrm{IgG}_{3}$ e $\mathrm{IgG}_{4}$. Esses resultadas estão em concordância com outros trabalhos na literatura (Gondim et al., 2012; Yavuz et al., 2006) que encontraram pH de maior adsorção de IgG no intervalo do $\mathrm{pI}$ da $\mathrm{IgG}$.

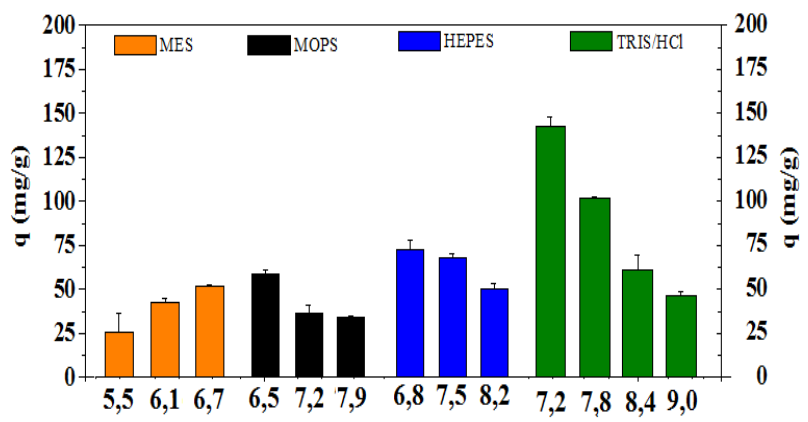

Figura 1 - Adsorção de IgG em QAE ${ }_{\mathrm{v}}$ nos tampões: MES, MOPS, HEPES e TRIS-HCl.

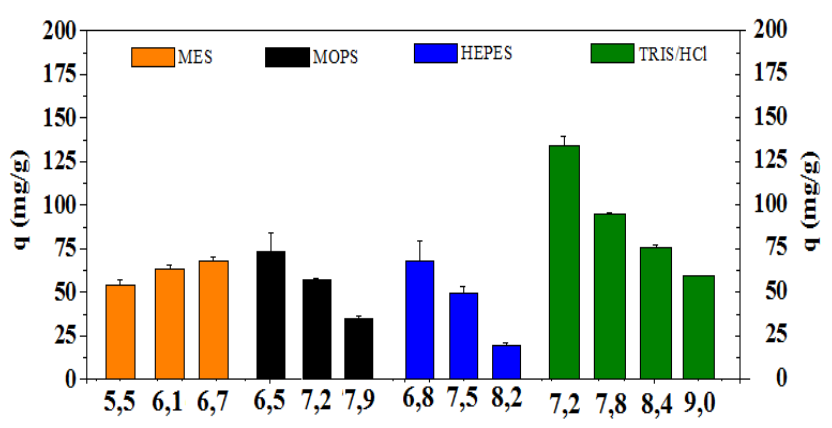

Figura 2 - Adsorção de IgG em QAE $\mathrm{a}_{\mathrm{a}}$ nos tampões: MES, MOPS, HEPES e TRIS-HCl.

A Tabela 1 apresenta uma comparação com os valores das quantidades adsorvidas de IgG nos dois materiais $\left(\mathrm{QAE}_{\mathrm{a}}\right.$ e $\mathrm{QAE}_{\mathrm{v}}$ ) destacando o $\mathrm{pH}$ de maior adsorção nos quatro tampões. Destaca-se os resultados com o tampão TRIS/HCl $(\mathrm{pH} 7,2)$, onde os valores de adsorção de $\operatorname{IgG}$ foram muito superiores aos demais. Para os próximos ensaios escolheu-se trabalhar com os tampões MOPS, HEPES e TRIS/HCl para investigar os parâmetros no equilíbrio de adsorção.

Tabela 1 - Resultados de maiores quantidade adsorvidas de $\mathrm{IgG}$ em $\mathrm{QAE}_{\mathrm{a}}$ e $\mathrm{QAE}_{\mathrm{v}}$ no $\mathrm{pH}$ ideal de cada tampão estudado.

\begin{tabular}{ccccccccc}
\hline \multirow{2}{*}{ Adsorvente } & \multicolumn{2}{c}{$\begin{array}{c}\text { HEPES } \\
(\mathrm{pH} \mathrm{6,8})\end{array}$} & \multicolumn{2}{c}{$\begin{array}{c}\text { MOPS } \\
(\mathrm{pH} \mathrm{6,5})\end{array}$} & \multicolumn{2}{c}{$\begin{array}{c}\text { MES } \\
(\mathrm{pH} \mathrm{6,7)}\end{array}$} & \multicolumn{2}{c}{$\begin{array}{c}\text { TRIS/HCl } \\
(\mathrm{pH} 7,2)\end{array}$} \\
\cline { 2 - 9 } & $\begin{array}{c}\mathrm{q} \\
(\mathrm{mg} / \mathrm{g})\end{array}$ & erro & $\begin{array}{c}\mathrm{q} \\
(\mathrm{mg} / \mathrm{g})\end{array}$ & erro & $\begin{array}{c}\mathrm{q} \\
(\mathrm{mg} / \mathrm{g})\end{array}$ & erro & $\begin{array}{c}\mathrm{q} \\
(\mathrm{mg} / \mathrm{g})\end{array}$ & erro \\
\hline QAE $_{\mathrm{a}}$ & 68,18 & 11,0 & 73,33 & 10,8 & 67,69 & 2,4 & 133,81 & 5,4 \\
& & & & & & & & \\
QAE $_{\mathrm{v}}$ & 72,58 & 5,5 & 58,48 & 2,3 & 51,73 & 0,8 & 142,28 & 5,9 \\
\hline
\end{tabular}

\subsection{Isotermas de adsorção de IgG}

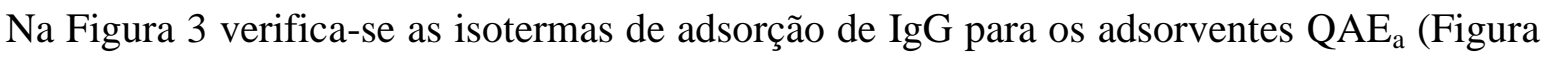
3.1) e QAE $_{\mathrm{v}}$ (Figura 3.2). Nos dois materiais verificou-se que no tampão TRIS/HCl, a adsorção de IgG foi superior aos demais, esses resultados são apoiados pelos resultados anteriores (teste do 
pH), onde o tampão TRIS/HCl apresentou elevado destaque. Para os outros tampões observou-se uma quantidade adsorvida de IgG muito significativa, superior a $100 \mathrm{mg} / \mathrm{g}$.

Os modelo de Langmuir e Langmuir-Freundlich se ajustaram aos dados experimentais proporcionando os parâmetros destacados nas Tabelas 2 e 3. As quantidades máximas de $\operatorname{IgG}$ adsorvidas foram acima de $250 \mathrm{mg} / \mathrm{g}$ em ambos adsorventes no tampão TRIS/HCl. Os parâmetros $\mathrm{K}_{\mathrm{D}}$ e $\mathrm{K}_{\mathrm{DLF}}$ são importantes, pois valores entre $10^{-5}$ e $10^{-8} \mathrm{M}$ indicam que o adsorvente possui forte ligação com a molécula alvo e são definidos como ligantes de afinidade. De acordo com os resultados das Tabelas 2 e 3 esses dois adsorvente podem ser considerado como de ligantes de afinidade por possuírem valores na ordem de $10^{-6} \mathrm{M}$ para as constantes de dissociação $\left(\mathrm{K}_{\mathrm{D}}\right.$ e $\mathrm{K}_{\mathrm{DLF}}$ ). Para os outros tampões (MOPS e HEPES) verificou-se quantidade adsorvida de IgG similares, com destaque ao adsorvente $\mathrm{QAE}_{\mathrm{a}}$ no tampão HEPES com quantidade máxima de IgG adsorvida de $192,8 \mathrm{mg} / \mathrm{g}$.
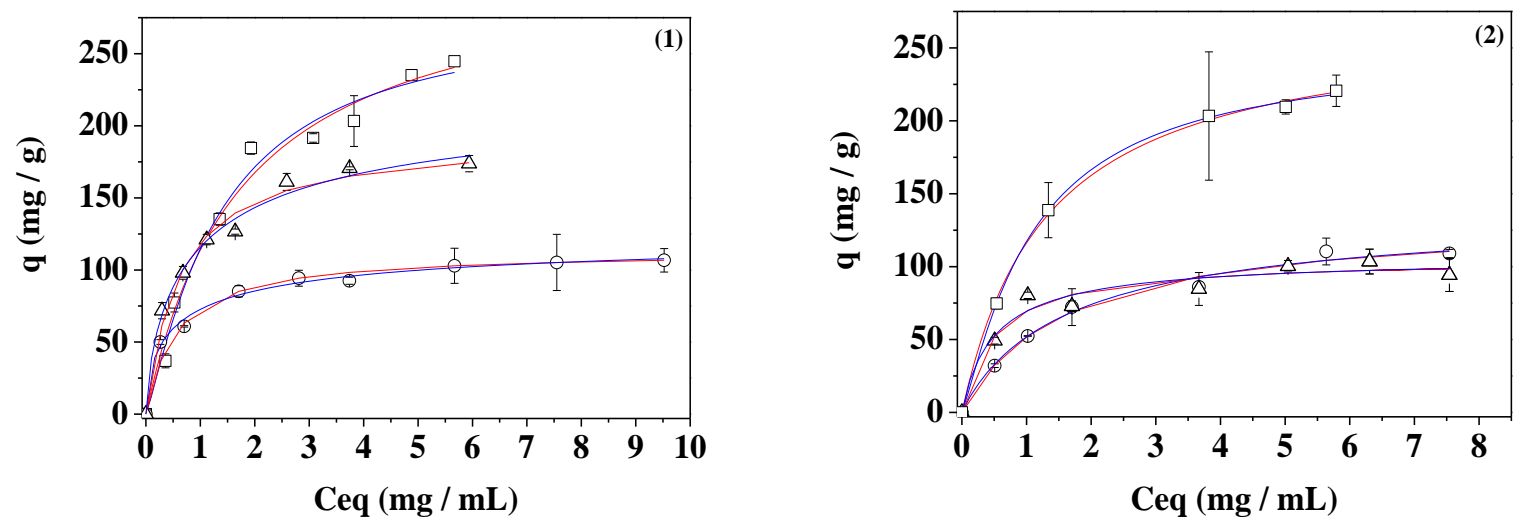

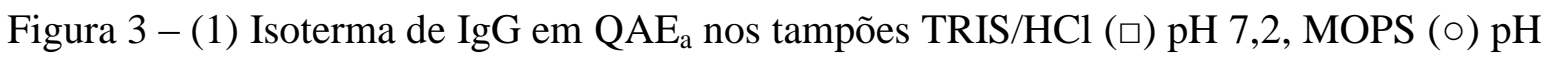
6,5 e HEPES $(\Delta) \mathrm{pH}$ 6,8. (2) Isoterma de IgG em QAE $\mathrm{V}_{\mathrm{v}}$ nos tampões TRIS/HCl ( $\square$ ) pH 7,2, MOPS (०) pH 6,5 e HEPES ( $\Delta$ ) $\mathrm{pH}$ 6,8. Modelos de ajuste: Langmuir (linha vermelha) e Langmuir-Freundlich (linha azul).

Tabela 2 - Parâmetros de ajuste pelos modelos de Langmuir e Langmuir -Freundlich com o adsorvente QAE $\mathrm{a}_{\mathrm{a}}$ nos tampões MOPS (pH 6,5), HEPES (pH 6,8) e TRIS/HCl (pH 7,2).

\begin{tabular}{|c|c|c|c|c|c|c|c|c|c|c|c|c|}
\hline & \multicolumn{4}{|c|}{$\begin{array}{c}\text { MOPS } \\
(25 \mathrm{mM})\end{array}$} & \multicolumn{4}{|c|}{$\begin{array}{l}\text { HEPES } \\
(25 \mathrm{mM})\end{array}$} & \multicolumn{4}{|c|}{$\begin{array}{c}\text { TRIS/HCl } \\
(25 \mathrm{mM})\end{array}$} \\
\hline & $\mathrm{L}$ & erro & LF & erro & $\mathrm{L}$ & erro & LF & erro & $\mathrm{L}$ & erro & $\mathrm{LF}$ & erro \\
\hline$q_{m}(\mathrm{mg} / \mathrm{g})$ & 108,5 & 3,0 & 130,4 & 14,8 & 192,8 & 7,8 & 228,44 & 3,0 & 315,5 & 21,2 & 281,9 & 35,7 \\
\hline$K_{\mathrm{D}}\left(\mathrm{x} 10^{6} \mathrm{M}\right)$ & 2,83 & 0,4 & - & - & 4,18 & 0,6 & - & - & 0,72 & 0,10 & - & - \\
\hline$K_{\mathrm{DLF}}\left(\mathrm{x} 10^{6} \mathrm{M}\right)$ & - & - & 5,3 & 1,6 & - & - & 6,48 & 2,5 & - & - & 1,46 & 0,4 \\
\hline$n$ & - & - & 0,59 & 0,13 & - & - & 0,71 & 0,4 & - & - & 1,17 & 0,23 \\
\hline $\mathrm{R}^{2}$ & 0,98 & - & 0,99 & - & 0,99 & - & 0,99 & - & 0,98 & - & 0,99 & - \\
\hline$\chi^{2}$ & 22,7 & - & 10,15 & - & 56,7 & - & 43,9 & - & 157,7 & - & 149,1 & - \\
\hline
\end{tabular}

L- Langmuir e LF- Langmuir-Freundlich 
Tabela 3 - Parâmetros de ajuste pelos modelos de Langmuir e Langmuir -Freundlich com o adsorvente $\mathrm{QAE}_{\mathrm{v}}$ nos tampões MOPS (pH 6,5), HEPES (pH 6,8) e TRIS/HCl (pH 7,2)

\begin{tabular}{c|c|c|c|c|c|c|c|c|c|c|c|c}
\hline & \multicolumn{4}{|c|}{\begin{tabular}{c} 
MOPS \\
\multirow{2}{*}{}
\end{tabular}} & \multicolumn{4}{|c|}{ HEPES } & \multicolumn{3}{c|}{ TRIS/HCl } \\
\cline { 2 - 13 } & L & erro & LF & erro & L & erro & LF & erro & L & erro & LF & erro \\
\hline$q_{m}(\mathrm{mg} / \mathrm{g})$ & 133,5 & 6,6 & 138,3 & 25,6 & 92,80 & 4,5 & 85,4 & 4,12 & 269,8 & 5,2 & 249,0 & 8,9 \\
$K_{\mathrm{D}}\left(\mathrm{x} 10^{6} \mathrm{M}\right)$ & 10,5 & 1,6 & - & - & 2,24 & 0,8 & - & - & 0,76 & 0,05 & - & - \\
$K_{\mathrm{DLF}}\left(\mathrm{x} 10^{6} \mathrm{M}\right)$ & - & - & 11,1 & 3,6 & - & - & 2,45 & 1,3 & - & - & 1,12 & 0,10 \\
$n$ & - & - & 0,94 & 0,3 & - & - & 0,14 & 0,12 & - & - & 1,18 & 0,09 \\
$\mathrm{R}^{2}$ & 0,99 & - & 0,99 & - & 0,96 & - & 0,97 & - & 0,99 & - & 0,99 & - \\
$\chi^{2}$ & 20,2 & - & 25,0 & - & 53,8 & - & 45,6 & - & 11,21 & - & 6,9 & - \\
\hline
\end{tabular}

L-Langmuir e LF-Langmuir-Freundlich

\subsection{Leito fixo com IgG e os adsorventes $\mathrm{QAE}_{\mathrm{a}}$ e $\mathrm{QAE}_{\mathrm{v}}$}

A Figura 4 mostra os perfis do comportamento da adsorção de $\operatorname{IgG}$ no leito fixo com as fases estacionárias $\mathrm{QAE}_{\mathrm{a}}$ (Figura 4.1) e $\mathrm{QAE}_{\mathrm{v}}$ (Figura 4.2) para um volume de injeção de IgG de $10 \mathrm{~mL}$ e concentração de $1,0 \mathrm{mg} / \mathrm{mL}$, representando, em torno de $10 \mathrm{mg}$ de IgG (em massa) injetada na coluna. Após os ensaios em batelada, os experimentos em leito fixo confirmaram o potencial dos corantes reativo verde 5 e reativo azul 4 imobilizados em quitosana/alginato epoxidado $\left(\mathrm{QAE}_{\mathrm{a}}\right.$ e $\left.\mathrm{QAE}_{\mathrm{v}}\right)$ em adsorver a proteína $\mathrm{IgG}$.
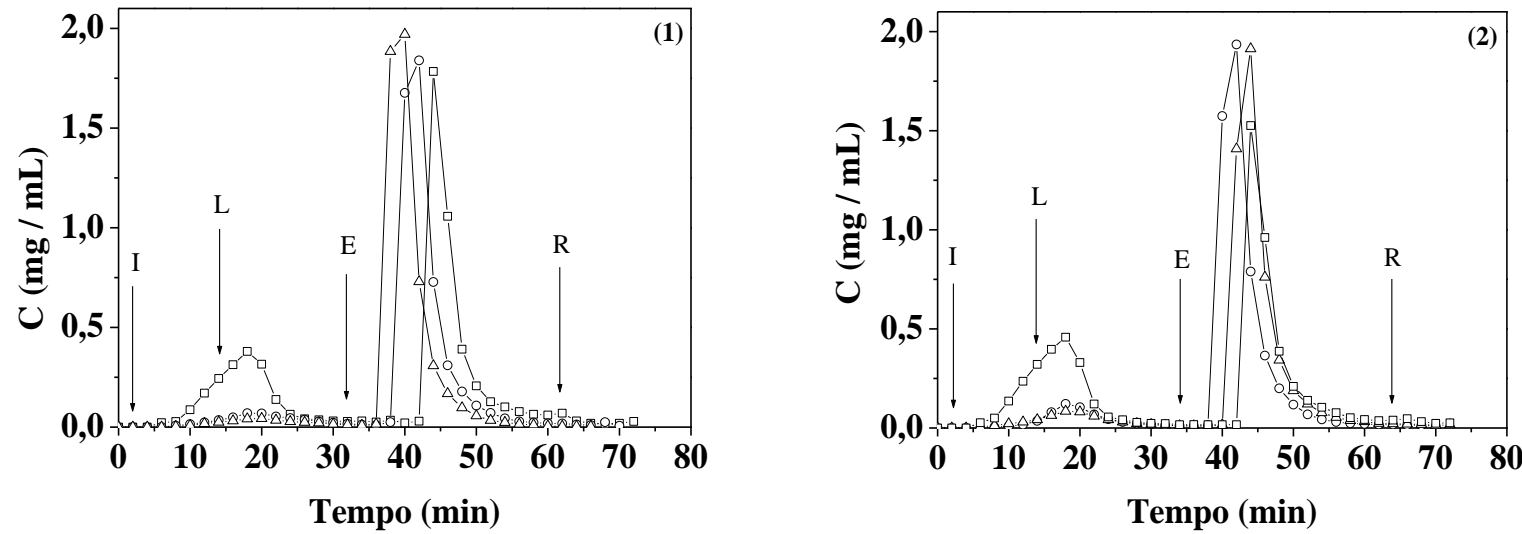

Figura 4 - Ensaios em leito fixo com IgG e os adsorventes $\mathrm{QAE}_{\mathrm{a}}(1)$ e $\mathrm{QAE}_{\mathrm{v}}(2)$ nos tampões TRIS/HCl (口) pH 7,2, MOPS (०) pH 6,5 e HEPES ( $\Delta$ ) pH 6,8 com injeção de $10 \mathrm{~mL}$ de $\operatorname{IgG}(1,0 \mathrm{mg} / \mathrm{mL})$.

O primeiro pico que pode ser visualizado na Figura 4 caracteriza a quantidade de proteínas que estão passando pela fase estacionária sem ser adsorvida. $\mathrm{O}$ segundo pico representa a 


\section{9 a 22 de outubro de 2014 \\ Florianópolis/SC}

dessorção da proteína (IgG) que foi adsorvida nos dois adsorventes. Observou-se um elevado pico de dessorção indicando alta quantidade de IgG foi adsorvida em todos os tampões estudados.

O tampão que proporcionou os melhores resultados de IgG no leito foi o HEPES (pH 6,8), onde o percentual de IgG retida na fase estacionária foi de 90,0 e 88,0\%, respectivamente com os adsorventes $\mathrm{QAE}_{\mathrm{a}}$ e $\mathrm{QAE}_{\mathrm{v}}$. Esses resultados significam que para cada $10 \mathrm{mg}$ de IgG injetada (diluída no tampão HEPES) no leito fixo com $\mathrm{QAE}_{\mathrm{a}}$ e $\mathrm{QAE}_{\mathrm{v}}$, aproximadamente 90,0 \% foram adsorvidas e recuperadas na eluíção (pico 2, Figura 4).

Com esses resultados pode-se afirmar que os dois adsorventes $\mathrm{QAE}_{\mathrm{a}}$ e $\mathrm{QAE}_{\mathrm{v}}$ possuem alto potencial em adsorver IgG e ensaios futuros com amostras de soro humano serão realizados a fim de se confirmar a seletividade por IgG do soro humano. No trabalho realizado por Gondim et al., (2012) os autores utilizaram uma matriz de quitosana/alginato epoxidado com o corante cibacron blue F3GA como ligante de afinidade e obtiveram resultados satisfatórios para purificação de $\operatorname{IgG}$ humana.

\section{CONCLUSÃO}

Foi possível concluir a partir dos resultados desse trabalho que os corantes reativo verde 5 e reativo azul 4 atuaram de forma eficiente como ligantes de afinidade propiciando elevada capacidade de adsorção por IgG. Constatou-se que os diferentes tampões utilizados tiveram influência na adsorção de IgG nos dois adsorventes utilizados. A adsorção de IgG no tampão TRIS/HCl foi superior aos demais tampões nas curvas de isoterma de adsorção. No entanto para os ensaios em leito fixo a adsorção de IgG em tampão HEPES foi superior aos demais tampões e com um percentual elevado de IgG retida nos dois adsorventes, em torno de 90,0\%. Tais resultados foram satisfatório para o propósito da busca de novos adsorventes com alta seletividade por domínios específicos da IgG.

\section{REFERENCIAS}

AMERSHAM. Antibody Purification Handbook. Amersham Biosciences, 2002.

BAYRAMOGLU, G.; SENEL, A. U.; ARICA, M. A. Adsorption of IgG on spacer-arm and 1arginine ligand attached poly (GMA/MMA/EGDMA). J. Applied Polym. Sci.. v. 104, p. 672679, 2007.

BRESOLIN, I. T.; SOUZA, M. C. M.; BUENO, S. M. A. A new process of IgG purification by negative chromatography: adsorption aspcets of human serum proteins onto $\omega$-aminodecylagarose. J. Chrom. B, v. 878, p. 2087-2093, 2010.

BURNOUF, T.; RADOSEVICH, M. Affinity chromatography in the industrial purification of plasma proteins for therapeutic use. J. Biochem. Biophys. Meth.. v. 49, p. 575-586, 2001.

DENIZLI, A.; PISKIN, E. Dye-ligand affinity systems. J. Biolchem. Bioph. Meth. v. 49, p. 391- 
416, 2001.

GONDIM, DIEGO R. ; LIMA, LUANA P. ; DE SOUZA, MARIA C. M. ; BRESOLIN, IGOR T. L.; ADRIANO, WELLINGTON S. ; AZEVEDO, DIANA C. S. ; SILVA, IVANILDO J. Dye ligand epoxide chitosan/alginate: a potential new stationary phase for human IgG purification. Adsorp. Sci. Technol. v. 30, p. 701 - 712, 2012.

VIJAYALAKSHMI, M. A. Pseudobioespecific ligand affinity chromatography. Trends Biotechnol. v. 7, p. 71, 1989.

WONGCHUPHAN, R.; TEY, T. B.; TAN, W. S.; TAIP, F. S.; KAMAL, S. M. M.; LING, T. C. Application of dye-ligands affinity adsorbent in capturing of rabbit immunoglobulin G. Biochem. Eng. J. v. 45, p. 232-238, 2009.

YAVUZ, H.; AKGÖL, S.; SAY, R.; DENIZLI, A. Affinity Separation of Immunoglobulin G Subclasseson Dye Attached poly (hydroxypropyl methacrylate) beads. Intern. J. Biol. Macromol.v. 39, p. 303-309, 2006. 